\title{
Failure to Deploy
}

National Cancer Institute

\section{Source}

National Cancer Institute. Failure to Deploy. NCI Thesaurus. Code C63183.

Problem associated with the inability of the medical device to be positioned in a specified location. 